\title{
Лідія Кайдалова
}

доктор педагогічних наук, професор, завідувач кафедри освітніх та інформаційних технологій Національного фармацевтичного університету; Харків, Україна

ORCID: 0000-0003-4693-678X

E-mail: lkaidalova@ukr.net

\section{Наталія Науменко}

кандидат педагогічних наук, старший викладач кафедри освітніх та інформаційних технологій Національного фармацевтичного університету; Харків, Україна

ORCID: 0000-0003-0658-1769

E-mail: naumenkonv.77@gmail.com

\section{НАПРЯМИ ВДОСКОНАЛЕННЯ МЕТОДИК ВИКЛАДАННЯ НАВЧАЛЬНИХ ДИСЦИПЛІН МАГІСТРАМ ОСВІТНІХ, ПЕДАГОГІЧНИХ НАУК}

Анотаиія: розглянуто проблеми професійної підготовки магістрів освітніх, педагогічних наук у закладах вищої освіти; досліджено теоретико-методичні засади удосконалення методик викладання навчальних дисциплін у професійній підготовці магістрів; доведено необхідність їх модернізації за рахунок впровадження інноваційних методів і технологій навчання, діалогічної взаємодії суб’єктів освітнього процесу. Реалізовано методику викладання навчальних дисциплін магістрам освітніх, педагогічних наук в умовах дистанційного навчання.

Ключові слова: методика викладання, магістр освітніх, педагогічних наук, викладач, вища освіта, заклад вищої освіти.

\section{Lydiya Kaydalova}

doctor of pedagogical sciences, professor, head of the department of educational and information technologies, National University of Pharmacy; Kharkiv, Ukraine E-mail: lkaidalova@ukr.net

\section{Nataliya Naumenko}

candidate of pedagogical sciences, senior lecturer of educational and information technologies department, National University of Pharmacy; Kharkiv, Ukraine

E-mail:naumenkonv.77@gmail.com

\section{DIRECTIONS FOR IMPROVING THE METHODOLOGY OF TEACHING EDUCATIONAL DISCIPLINES TO MASTER OF EDUCATION, PEDAGOGICAL SCIENCES}

Abstract: the article examines the problems of professional training of masters in pedagogical sciences in higher education institutions; analyzes theoretical and methodological bases for improving the methods of teaching academic disciplines in the professional training of (C) Лідія Кайдалова, Наталія Науменко, 2021 
masters; proves the necessity of their modernization by introducing innovative methods and teaching technologies, dialogical interaction of the subjects of the educational process. Implemented the methodology of teaching academic disciplines to masters of educational, pedagogical sciences in a distance learning environment.

Keywords: teaching methodology, master of education, pedagogical sciences, teacher, higher education, institution of higher education.

\section{Лидия Кайдалова, Наталья Науменко}

\section{НАПРАВЛЕНИЯ СОВЕРШЕНСТВОВАНИЯ МЕТОДИК ПРЕПОДАВАНИЯ УЧЕБНЫХ ДИСЦИПЛИН МАГИСТРАМ ОБРАЗОВАТЕЛЬНЫХ, ПЕДАГОГИЧЕСКИХ НАУК}

Аннотащия: рассмотрены проблемы профессиональной подготовки магистров образовательных, педагогических наук в учреждениях высшего образования; исследовано теоретико-методические основы совершенствования методик преподавания учебных дисциплин в профессиональной подготовке магистров; доказана необходимость их модернизации за счет внедрения инновационных методов и технологий обучения, диалогического взаимодействия субъектов образовательного процесса. Реализовано методику преподавания учебных дисциплин магистрам образовательных, педагогческих наук в условиях дистанционного обучения.

Ключевые слова: методика преподавания, магистр образовательных, педагогических наук, преподаватель, высшее образование, учреждение высшего образования.

\section{Lydiya Kaydalova, Nataliya Naumenko}

An extended abstract of a paper on the subject:

"Directions for improving the methodology of teaching educational disciplines to master of education, pedagogical sciences"

Problem setting. Improvement of teaching methods of academic disciplines in Master's training of educational, pedagogical sciences is based on the best achievements of domestic and foreign training and stipulates research and implementation of educational innovations taking into account modern trends and requirements for Master's training. Training of professionally competent specialists, who are competitive in the labor market, depends on teachers' professional competence and pedagogical skills, professional and general culture, innovative and flexible thinking, professionally important and personal qualities, and the ability for continuous self-improvement and self-development. That is why we continue to research and improve the methods of teaching academic disciplines in the preparation of masters in educational, pedagogical sciences.

Recent research and publications analysis demonstrates increased attention to professional training and methods of teaching academic disciplines to master's degree candidates in higher education institutions.

Theoretical analysis of the research problem showed that separate issues of master's degree training in higher education institutions were reflected in the scientific works of A. Antonova, L. Kaidalova, V. Kravchenko,

Batechko, N., Myronchuk, N., et al. $[1 ; 3 ; 6 ; 8 ; 11]$.

Methodology of teaching in higher education is reflected in the scientific works of O. Antonova, N. Bulhakova, 
A. Dubaseniuk, G. Kozlova, et al. [1; 4; 5; 7]; the issues of methodology of teaching professional disciplines were researched by A. Vinoslavska, N. Kravchuk, A. Malykhin, et al. $[9 ; 10 ; 14]$.

Analysis of teaching methods that are used in special education, teaching disciplines in higher education paid attention by foreign scientists Uzunboylu H., Özcan, D., Winberg C., Baiduc, Rachael R., Robert A. [18-20].

Mikhailichenko, A. singles out the methodology of teaching a subject as “... a separate branch of pedagogical science, which is a separate theory of learning (private didactics), due to the characteristics and specifics of the acquisition of knowledge, skills and abilities of a separate subject" [12].

Kravchuk, H. and Koval, A. consider teaching methodology in higher education from the angle of forming and strengthening students' positive motivation to the learning process. Each teacher should take into account the principle of realizing the unity of theory and practice, promoting the formation of students' theoretical knowledge through independent creative search, and practical skills in the process of adapting theoretical knowledge to the future profession through the use of interactive teaching methods[9].

Bulhakova, H.notes that the methodology of teaching in higher education should implement the objectives of higher education, noting that the choice of purpose in any academic discipline depends to the greatest extent on the selection of the content of educational information and the use on this basis of adequate forms, methods and means of teaching [4].

In a scientific study of innovative techniques in legal education, N. Articutsa notes that among them the most demanded in today's market of educational services are active and interactive teaching techniques. [2].

We are impressed by N. Romashev's point of view in studying the differences between pedagogical technologies and methods, where the author believes that teaching methods are more permanent than technologies, they change along with the changes in the educational idea. Technologies have a large number of variations even within a single methodology [15].

Thus, the analysis of the concept of "Methodology of teaching in higher education institutions" allows us to state that in the methodology of teaching disciplines we understand the implementation of a set of principles, rules, techniques, methods and means, taking into account the features of the academic discipline.

Paper objective. The formulation of the objectives of the article lies in the study of theoretical and methodological foundations in order to improve the methods of teaching academic disciplines in the professional training of masters of educational, pedagogical sciences.

Paper main body. Presentation of the main material of the study with a full justification of the obtained scientific results. The training of masters of educational, pedagogical sciences on the educational program "Pedagogy of Higher Education" is aimed at forming integral, general and professional competencies, development of professionally important qualities of a teacher.

In the process of researching the methods of teaching academic disciplines for masters of educational, pedagogical sciences disciplines "Pedagogical skill of a teacher" and "Methods of teaching in higher education" were selected from the mandatory components of the educational program "Pedagogy of Higher Education".

The authoring methodology of teaching the discipline "Pedagogical skill of a teacher" to masters of educational, pedagogical sciences led to a revision of the content in accordance with the general and professional competencies, the introduction of modern methods of interactive teaching. In place of informative, explanatory, introductory lectures during the teaching preference was given to dialogic, interactive and problembased lectures. Methodology of practical classes was enriched with didactic games, trainings, cases. 
To improve the methods of teaching subjects "Pedagogical skill of a teacher" and "Methodology of teaching in higher education" we revised and improved the contents of disciplines, justified and introduced innovative methods and teaching technologies to ensure dialogical interaction of subjects of the educational process, developed individual and group tasks for independent work of education applicants.

During the practical sessions, the emphasis was made on developing of professional competencies of the applicants, where they were not only acquainted with modern methods of teaching, but they themselves were participants in an innovative educational environment, having the opportunity to feel the features of each method from the inside, their advantages and disadvantages, thereby forming important professional and personal qualities.

At each seminar session modern methods of teaching were used, which used in accordance with the goals and objectives of the lesson, but all were aimed at the deepest mastering of knowledge, the formation of practical skills in the choice and application of effective tools (methods, forms, technologies) to implement learning objectives. The organization of group activity during the class promoted the exchange of experience and knowledge; contributed to the establishment of communication links between the participants of the training activities; promoted the active cognitive activity of future specialists.

During the quarantine, teaching of the discipline "Methodology of teaching in higher education" was carried out remotely, using the platform Moodle. For this purpose teaching materials were developed and placed,

Постановка проблеми у загальному вигляді та iï зв'язок із важливими науковими чи практичними завданнями. Посилення вимог із боку держави та суспільства до якості професійної підготовки магістрів освітніх, педагогічних наук викликане значними перебудовами у різних сферах людської діяльності та including the curriculum, syllabus, presentations and lecture notes, video clips, fragments of classes, materials for practical exercises and for independent work, links to sources, tasks for independent work, materials on all types of control.

Zoom service was used for conducting online classes, which allowed to conduct lectures, practical and seminar classes, individual consultations, to control the level of academic achievements of the applicants.

In order to determine the methods of teaching academic disciplines conducted a survey of 74 applicants for master's degree in the specialty 011 Education, Education Sciences, educational program "higher education pedagogy" fulltime, evening and part-time form of education.

The results of the survey allowed to evaluate the methodology of teaching the discipline "Methodology of teaching in higher education" with improved methods by enriching the content, the introduction of modern pedagogical technologies and interactive methods.

Conclusions of the research. Analyzed scientific papers on the topic of research, improved and implemented methods of teaching academic disciplines "Pedagogical skill of a teacher" and "Methods of teaching in higher education institutions" in the professional training of masters of educational pedagogical sciences by enriching the content, changing the methods of lecturing with the strengthening of interactive learning, practical implementation of modern pedagogical technologies during classes, the introduction of $e$ learning technologies.

визначається сучасними потребами ринку праці. Метою вищої освіти Закону України "Про вищу освіту" встановлено підготовку “...конкурентоспроможного людського капіталу для високотехнологічного та інноваційного розвитку країни, самореалізації особистості, забезпечення потреб суспільства, ринку праці 
та держави у кваліфікованих фахівцях" [13], що зумовлює необхідність перегляду змісту та методичного забезпечення обов'язкового та вибіркового компонентів освітніх програм, форм, методів та технологій навчання. Відповідно до Закону України "Про вищу освіту" майбутні фахівці мають здобути “...високий рівень наукових (творчих, мистецьких) професійних i загальних компетентностей, які необхідні для діяльності за певною спеціальністю чи у певній галузі знань” [13]. У Стратегії розвитку вищої освіти України на 2021-2031 роки наголошується про проведені дослідження щодо невідповідності структури підготовки поточним i перспективним потребам ринку праці та вказується на невідповідність галузевих стандартів, кваліфікаційних вимог потребам сучасності, нестачу практичних професійних навичок, відірваність теоретичних знань від практики [17].

Реформування системи вищої освіти та нова Стратегія розвитку вищої освіти України на 2021-2031 роки радикально змінюють основні принципи навчання та вимагають удосконалення методик викладання навчальних дисциплін у підготовці магістрів освітніх, педагогічних наук, що грунтується на кращих надбаннях вітчизняної та зарубіжної підготовки, зумовлює дослідження й впровадження освітніх інновацій iз врахуванням сучасних тенденцій вимог до магістерської підготовки. Підготовка професійно компетентних фахівців, конкуренттоспроможних на ринку праці залежить від професійної компетентності та педагогічної майстерності викладачів, професійної та загальної культури, інноваційного та гнучкого мислення, професійно важливих та особистісних якостей, здатності до постійного самовдосконалення та саморозвитку. Саме тому ми продовжуємо дослідження та удосконалення методик викладання навчальних дисциплін у підготовці магістрів освітніх, педагогічних наук.

Аналіз останніх досліджень і пуб- лікацій, в яких започатковано розв'язання цієї проблеми і на які спирається автор, свідчить про посилену увагу до професійної підготовки, зокрема методик викладання навчальних дисциплін здобувачам магістерського ступеня у закладах вищої освіти.

Питання методики викладання фахових дисциплін у закладах вищої освіти привертали увагу багатьох вітчизняних та зарубіжних науковців.

Теоретичний аналіз із проблеми дослідження засвідчив, що окремі питання підготовки магістрів у закладах вищої освіти знайшли відображення у наукових працях О. Антонової, Н. Батечко, Л. Кайдалової, В. Кравченко, Н. Мирончук та ін. [1; 3; 6; 8; 11]. Методика викладання у вищій школі відображена у наукових роботах О. Антонової, Г. Козлової Н. Булгакової, О. Дубасенюк, та ін. [1; 4; 5; 7]; питання методик викладання фахових дисциплін досліджували Н. Кравчук, О. Малихін, О. Винославська та ін. [9; 10;14].

Аналізу методів навчання, що використовуються в спеціальній освіті; навчанню викладання дисциплін у вищій освіті приділяли увагу зарубіжні науковці Uzunboylu H., Özcan, D., Winberg C., Baiduc, Rachael R., Robert A. [18-20].

Наведемо декілька прикладів розуміння сутності методики викладання вітчизняними науковцями.

Наприклад, О. Михайличенко у своїх наукових дослідженнях методику викладання предмета виділяє як “... окрему галузь педагогічної науки, яка являє собою окрему теорію навчання (приватну дидактику), обумовлену особливостями та специфікою набуття знань, умінь та навичок окремого предмета" [12].

У той час, Н. Кравчук та О. Коваль розглядають методику викладання у вищій школі під кутом формування та посилення позитивної мотивації у студентів до процесу навчання. Кожний викладач має враховувати принцип реалізації єдності теорії та практики, сприяючи формуванню теоретичних 
знань у здобувачів освіти шляхом самостійного творчого пошуку, а практичних навичок у процесі адаптації теоретичних знань до майбутнього фаху через використання інтерактивних методів навчання [9].

Зокрема, Н. Булгакова наголошує, що методика викладання у вищій школі має реалізовувати завдання вищої освіти, зазначаючи, що вибір мети в будь-якій навчальній дисципліні найбільшою мірою залежить від відбору змісту навчальної інформації та використання на цій основі адекватних форм, методів та засобів навчання [4].

У науковому дослідженні інноваційних методик в юридичній освіті Н. Артикуца зазначає, що серед них найбільш затребуваними на сьогоднішньому ринку освітніх послуг $є$ активні та інтерактивні методики навчання. Автор констатує, що наскільки суттєво зростає творча компонента освіти, активізується роль усіх учасників навчального процесу, зміцнюється творчо-пошукова самостійність студентів, особливої актуальності нині набули концепції проблемного та інтерактивного навчання. Під час такого навчання студент вступає у діалог із викладачем, виконує творчі, проблемні завдання, відповідає на запитання, що розвивають аналітичне і критичне мислення, ставить запитання викладачеві та іншим учасникам, тобто активізується творча співпраця викладача зі студентами [2].

Нам імпонуе точка зору Н. Ромашевої у дослідженні відмінностей у педагогічних технологіях та методиках, де авторка вважає, що методики навчання більш сталі, ніж технології, вони змінюються разом зі зміною освітньої ідеї. Технології мають велику кількість варіантів, навіть у межах однієї методики [15].

Таким чином, аналіз поняття “методика викладання у вищій школі” дає змогу констатувати, що під методикою викладання дисциплін ми розуміємо реалізацію сукупності принципів, правил, прийомів, методів і засобів, враховуючи особливості навчальної дисципліни.

Виділення не вирішених раніше частин загальної проблеми, котрим присвячується дана стаття. У статті порушена проблема удосконалення методик викладання навчальних дисциплін у професійній підготовці магістрів освітніх, педагогічних наук, враховуючи виклики сьогодення, вимоги з боку суспільства, стейкхолдерів та корис-тувачів освітніх послуг до професійної підготовки у магістратурі.

Формулювання цілей статті (постановка завдання) $\epsilon$ напрями вдосконалення методик викладання навчальних дисциплін у професійній підготовці магістрів освітніх, педагогічних наук.

Виклад основного матеріалу дослідження 3 повним обгрунтуванням отриманих наукових результатів. Підготовка магістрів освітніх, педагогічних наук за освітньою програмою "Педагогіка вищої школи" спрямована на формування інтегральної, загальної та фахових компетентностей, розвитку професійно важливих якостей викладача [16].

Враховуючи накопичений шістнадцятирічний практичний досвід викладання в процесі професійної підготовки магістрів освітніх, педагогічних наук, було обрано для дослідження методик викладання навчальні дисципліни "Педагогічна майстерність викладача" та "Методика викладання в вищій школі" 3 обов'язкового компоненту освітньої програми "Педагогіка вищої школи".

Авторська методика викладання навчальної дисципліни "Педагогічна майстерність викладача" магістрам освітніх, педагогічних наук зумовила перегляд змісту відповідно до загальних та фахових компетентностей, упровадження сучасних методів інтерактивного навчання. На зміну лекціям інформаційним, пояснювальним, оглядовим під час викладання перевагу надано діалоговим, інтерактивним та проблемним лекціям. Методику проведення практичних занять було збагачено дидактичними іграми, тренінгами, кейсами.

Для удосконалення методик викладання навчальних дисциплін "Педагогіч- 
на майстерність викладача" та "Методика викладання у вищій школі" нами було переглянуто та удосконалено зміст дисциплін, обгрунтовано та впроваджено інноваційні методи та технології навчання 3 метою забезпечення діалогічної взаємодії суб'єктів освітнього процесу, розроблено індивідуальні та групові завдання для самостійної роботи здобувачів освіти.

Під час практичних занять акцент

було зроблено на формування професійних компетентностей здобувачів, i вони не тільки знайомились із сучасними методиками викладання, але й самі були учасниками інноваційного освітнього середовища, де мали можливість відчути особливості кожного методу із середини, їхні переваги та недоліки, тим самим формуючи важливі професійні та особистісні якості.

Під час практичного заняття з теми “Форми, методи та засоби навчання у вищій школі" навчальної дисципліни "Методика викладання у вищій школі", метою якого було формування умінь та навичок володіння методами, формами та засобами навчання; вибору та застосування ефективних методів навчання в освітньому процесі у вищій школі та ін., нами було реалізовано методи фронтальної дискусії, групової роботи за методом "Мозаїка", метод групової діяльності "Килимок ідей" та ін. Цікавою виявилась фронтальна дискусія 3 метою 3'ясування сутності освітнього процесу в закладах вищої освіти, його призначення, планування та організація. Обговорення було представлено питаннями щодо технологічності освітнього процесу та взаємозв'язку понять “технологія”, “методика", “методологія”. Розгляд та обговорення цих питань спонукали здобувачів освіти мобільно мислити, дали можливість здобувачам висловити власну позицію, проявити себе. Дискусія мотивувала їх до пошуку відповідей на складні запитання, підвищуючи таким чином якість засвоєння навчального матеріалу, а також формуючи готовність до професійної діяльності.
Відповідно до мети та завдань заняття 3 теми "Інноваційні методики викладання" навчальної дисципліни "Методика викладання у вищій школі" було організовано та проведено заняття за методом “Круглий стіл”. Проведення круглого столу передбачало попередню підготовку здобувачів магістерського рівня, тому для самостійного опрацювання напередодні заняття їм було надано для розгляду п'ять наукових статей із проблем інноваційної освіти (Н. Артикуца "Інноваційні методики викладання дисциплін у вищій юридичній освіті", Ю. Бисторова "Інноваційні методи навчання у вищій школі”; М. Кляп "Імплементація інновацій-них методів у навчальний процес ВН3 як ознака інноваційного університету"; Н. Кошечко "Інноваційні освітні технології навчання та викладання у вищій школі”; М. Козяр "Інноваційні технології навчання в діяльності ВНЗ”). Також напередодні заняття в групі було обрано експертів серед магістрантів із конкретних питань теми, які, крім спільного завдання, готували ще окремі питання: чим, на вашу думку, $\epsilon$ освітні інновації; яка роль інновацій в освіті; як ви розумієте поняття "інноваційні методики"; що являють собою освітні інновації; які інноваційні методи $є$ найбільш дієвими у викладацькій діяльності викладача та інші. Нами було враховано, що магістранти не завжди активні під час обговорення проблемних питань. Як засвідчили результати круглого столу здобувачі володіли програмним матеріалом, висловлювали власну точку зору, аргументували своє бачення інновацій в освіті, демонстрували навички ведення дискусії, здійснювали педагогічну рефлексію.

Таким чином, на кожному семінарському занятті нами було використано сучасні методи навчання, які застосовувались відповідно до мети і завдань заняття, але всі були спрямовані на максимально глибоке засвоєння знань, формування практичних умінь щодо обрання та застосування дієвих інстру- 
ментів (методів, форм, технологій) для реалізації навчальних цілей. Організація групової діяльності під час заняття сприяла обміну досвідом i знаннями; встановленню комунікативних зв'язків між учасниками навчальної діяльності; активній пізнавальній діяльності майбутніх фахівців.

Нами вперше розроблено і впроваджено індивідуально-творчі завдання для самостійної роботи, серед яких: підготувати проєкт “Основні функції викладача вищої школи. Методична компетентність як складова професійно-педагогічної діяльності"; підготувати педагогічне есе на тему: "Традиційне та інтерактивне навчання. Переваги та недоліки"; підготувати приклади завдань для навчально-методичного комплексу дисципліни "Методика викладання у вищій школі"; розробити фраг-мент лекції-візуалізації (тема за вибором) та ін.

Зауважимо, що під час карантину викладання навчальної дисципліни "Методика викладання у вищій школі" здійснювалось дистанційно, 3 використанням платформи Moodle. Для цього було розроблено та розміщено навчально-методичні матеріали, серед яких робоча програма, силабус, презентації та конспектти лекцій, відео-ролики, фрагменти проведення занять, матеріали для практикних занять та для самостійної роботи, посилання на джерела, завдання для самостійної роботи, матеріали з усіх видів контролю.

Для проведення онлайн-занять використано сервіс Zoom, що надало можливість проводити лекції та практичні й семінарські заняття, індивідуальні консультації, здійснювати контроль рівня навчальних досягнень здобувачів.

Контроль та оцінювання виконаних завдань для самостійної роботи проде-монстрував високий рівень розуміння ролі викладача щодо організації освітнього процесу вищої школи, а також сформованість фахових компетентностей щодо володіння сучасними методами, формами та технологіями навчання. Під- сумковий модульний контроль було проведено за допомогою тестування.

3 метою з'ясування стану методики викладання навчальних дисциплін, зазначених у статті, після їхнього вивчення було проведено опитування 74 здобувачів магістерського ступеня, які отримували професійну підготовку на кафедрі освітніх, педагогічних наук Національного фармацевтичного університету зі спеціальності 011 Освітні, педагогічні науки, освітньої програми "Педагогіка вищої школи", денної, вечірньої та заочної форми навчання. Метою опитування було з'ясувати стан задоволеності здобувачів освіти від викладання навчальних дисциплін, а саме: застосування інноваційних методів та технологій навчання, які спрямовані на практичну реалізацію отриманих знань та оволодіння фаховими компетентностями.

Результати проведеного опитування дозволили оцінити методику викладання навчальних дисциплін "Методика викладання у вищій школі" та "Педагогічна майстерність викладача" із удосконаленими методиками шляхом збагачення змісту, упровадження сучасних педагогічних технологій та інтерактивних методів. Аналіз відповідей на запитання щодо задоволеності рівнем організації освітнього процесу під час вивчення навчальної дисципліни "Методика викладання у вищій школі" 92\% опитаних повністю влаштовує рівень організації освітнього процесу; 83,3\% відмітили інновації у читанні лекцій (бінарні, проблемні, лекціїпрес-конференції, інтерактивні лекції та ін.); 89,2\% респондентів звернули увагу на те, що під час практичних та семінарських занять викладачі застосовували інтерактивні методи навчання, які передбачають взаємодію всіх учасників освітнього процесу та спрямовані на відпрацювання практичних навичок; 73\% здобувачів магістерського ступеня зазначили, що використання удосконалених методик викладання із застосуванням освітніх інновацій та інтерактивного навчання суттєво вплинуло на рівень їхньої професійної 
підготовки, підвищило мотивацію та самомотивацію навчання, надали можливості проявити творчість, самостійність, спонукали до активності.

Висновки 3 даного дослідження та перспективи подальших розвідок у даному напрямку. Проаналізовано наукові праці за темою дослідження, удосконалено та впроваджено методики викладання навчальних дисциплін "Педагогічна майстерність викладача" та "Методика викладання у вищій школі” у

\section{Список літератури:}

1. Антонова О. Є. Педагогічні тех.нології та їх класифікація як наукова проблема. Сучасні технології в освіті. Ч. 1. Сучасні технології навчання / О. Є. Антонова // Наук.-допом. бібліогр. покажч. НАПН України, ДНПБ України імені В. О. Сухомлинського; упоряд.: Т. В. Філімонова, С. В. Тарнавська, І. О. Орищенко та ін. - Київ.-2015. Вип. № 2.-C. $8-15$

2. Артикуца Н. Інноваційні методики викладання дисциплін у вищій юридичній освіті [електронний ресурс]. Режим доступу:http://ekmair.ukma.edu.ua/ bitstream/handle/123456789/2424/Artikutsa_I nov.pdf;jsessionid=52A31E210A191B6760E C85CFB1103B92? sequence $=1$

3. Батечко Н. Г. Сучасні підходи до формування змісту підготовки майбутніх викладачів вищої школи в умовах магістратури / Н. Г. Батечко // Педагогічний процес: теорія і практика. -2013. - № 4. С. 5-20

4. Булгакова Н. Б., Рахманов В. О. Методика викладання у вищій школі / Н. Б. Булгакова, В. О. Рахманов // Навч. посіб. - Київ: НАУ. - 2012. - С. 204

5. Дубасенюк О. А., Антонова О. С. Методика викладання педагогіки /О. А. Дубасенюк, О. Є. Антонова // Курс лекцій. Вид. 2-ге, допов. - Ж.:Вид-во ЖДУ iм. I. Франка. - 2017. - С. 327

6. Кайдалова Л. Г. Методика проведення занять у вищому навчальному закладі / Л. Г. Кайдалова // Метод. рек. професійній підготовці магістрів освітніх педагогічних наук шляхом збагачення змісту, зміни методик читання лекцій із посиленням інтерактивного навчання, практичного втілення сучасних педагогічних технологій під час занять, упровадження технологій дистанційного навчання.

У подальшому наукові дослідження будуть спрямовані на пошук та дослідження освітніх інновацій із метою удосконалення професійної підготовки магістрів освітніх, педагогічних наук.

для викл. - Харків: Вид-во НФаУ. - 2004. - C. 60

7. Козлова Г. М. Методика викладання у вищій школі / Г. М. Козлова // Навч. посіб. - Одеса: ОНЕУ. - 2014. - C. 200

8. Кравченко В. М. Теоретичні i методичні засади модернізації професійної підготовки викладачів вищої школи в умовах магістратури / В. М. Кравченко // Дис ...д-ра пед. наук: 13.00.04. - 3.:- 2017. - С. 613

9. Методика викладання у вищій школі (мотивація навчальної діяльності): матеріали методичного семінару "Мотиваційний підхід до організації навчального процесу у вищій школі” / уклад.: Н. Я. Кравчук, О. С. Коваль. -Тернопіль: THEУ. - 2011. C. 81

10. Малихін О. В., Павленко І. Г., Лаврентьєва О. О., Матукова Г. І. Методика викладання у вищій школі / О. В. Малихін, I. Г. Павленко, О. О. Лаврентьєва, Г. І. Матукова // Навч. посіб. - С.: Дайфі. 2011. - C. 270

11. Мирончук Н. М. Особливості змісту підготовки магістрів спеціальності 011 "Освітні, педагогічні науки" ("Педагогіка вищої школи”) в Україні./ Н. М. Мирончук // Scientific Letters of Akademic Society of Michal Baludansky, 2018, № 3, Vol. 6, P. 99-103

12. Михайличенко О. В. Методика викладання суспільних дисциплін у вищій школі / Михайличенко О. В // Навч. посіб. Суми: СумДПУ. - 2009. - С. 122 
13. Закон України "Про вищу освіту від 01.07.2014” [електронний ресурс] / Міністерство освіти і науки України // Розпорядження № 1556-VII - 2014 - Режим доступу:https://zakon.rada.gov.ua/laws/show/ 1556-18\#Text

14. Психологія та методика викладання фахових дисциплін у вищій школі: робоча програма кредитного модуля, рівень вищої освіти другий (магістерський), спеціальність 075 "Маркетинг”, освітня програма ОНП "Промисловий маркетинг”, форма навчання заочна / КПІ ім. Ігоря Сікорського; уклад. О. В. Винославська. - К.: КПІ ім. I. Сікорського. - 2018. - С. 21[електронний ресурс]. - Режим доступу: https://ela.kpi.ua/handle/123456789/26481

15. Ромашева Н. Щодо проблеми впровадження педагогічних технологій у навчально-виховний процес. - [електронний ресурс]. - Режим доступу:https:// scienceandeducation.pdpu.edu.ua/doc/2009/3_ 2009/16.pdf.pdf

16. Стандарт вищої освіти. [електронний ресурс]. - Режим доступу: https://mon.gov.ua/ua/osvita/visha-osvita/ naukovo-metodichna-rada-ministerstvaosviti-i-naukiukrayini/zatverdzhenistandarti-vishoyi-osviti

17. Стратегія розвитку вищої освіти в Україні на 2021-2031 роки. [електронний ресурс]. - Режим доступу: https://mon.gov.ua/storage/app/media/rizne/20 20/09/25/rozvitku-vishchoi-osviti-v-ukraini02-10-2020.pdf

18. Baiduc, Rachael, R., Robert A. Linsen-meier, and Nancy Ruggeri (2016), "Mentored Discussions of Teaching: An Introductory Teaching Development Program for Future STEM Faculty”, Innovative Higher Education, №41(3)

19. Uzunboylu, H. \& Özcan, D. (2019), "Teaching methods used in special education: A content analysis study", International Journal of Cognitive Research in Science, Engineering and Education (IJCRSEE), №7(2), pp. 99-107

20. Winberg, C. (2018), et al. "Learning to teach STEM disciplines in higher education: a critical review of the literature", Teaching in Higher Education

\section{References:}

1. Antonova, O. Ye. (2015), "Pedagogical technologies and their classification as a scientific problem", Modern technologies in education. Ch. 1. Modern learning technologies: research assistant. bibliogr. Show, NAPS of Ukraine, DNPB of

Ukraine named after V. O. Sukhomlinsky, Kyiv, Issue 2, pp. 8-15

2. Artykutsa, N. "Innovative methods of teaching discipline in higher legal education", available at: http://ekmair.ukma. edu.ua/bitstream/handle/123456789/2424/Arti kutsa_Inov.pdf;jsessionid=52A31E210A191B 6760EC85CFB1103B92? sequence $=1$

3. Batechko, N. H. (2013), "Modern approaches to the formation of the content of training of future teachers of higher schools in the conditions of master's degree", Pedagogical process: theory and practice, № 4, pp. 5-20

4. Bulhakova, N. B., Rakhmanov, V. O. (2012), "Methods of teaching in high school", textbook. posib, Kyiv: NAU, p. 204

5. Dubaseniuk, O. A., Antonova, O. Ye. (2017), "Methods of teaching pedagogical courses: a course of lectures", added. Zhytomyr: ZhSU, Publishing House I. Franko, vol. 2 , p. 327

6. Kajdalova, L. H. (2004), "Methods of conducting classes in higher education: a method", rivers to off. K.: NUPh Publishing House, p. 60

7. Kozlova, H. M. (2014), "Methods of teaching in high school", textbook. posib. Odessa: ONEU, p. 200

8. Kravchenko, V. M. (2017), "Theore-tical and methodical bases of modernization of professional training of teachers of higher school in the conditions of a magistracy", dis. ... dr. ped., Science: 13.00.04., Zaporozhye, p. 613

9. "Methods of teaching in higher school (motivation of educational activity): materials of the methodical seminar", (2011), "Motivational approach to the organization of 
the educational process in higher school", compiled by: N. Ya. Kravchuk, O. E. Koval', Ternopil: TNEU, p. 81

10. Malykhin, O. V. , Pavlenko I. H., Lavrentyeva, O. O., Matukova H. I. (2011), "Methods of teaching in high school", textbook. posib., Simferopol: Dajfi, p. 270

11. Myronchuk, N. M. (2018), “Osoblyvosti zmistu pidhotovky mahistriv special'nosti", 011 "Educational, pedagogical science" ("Pedagogy of higher education") in Ukraine, Scientific letters of the Michal Baludansky Academic Society,no. 3, issue. 6, pp. 99-103

12. Mykhajlychenko, O. V. (2009), "Methods of teaching social sciences in higher education", textbook. posib. Sumy: Sumy State Pedagogical University, p. 122

13. Law of Ukraine "On Higher Education of 01.07.2014" (2014), Ministry of Education and Science of Ukraine, Order no. 1556-VII, available at: https://zakon.rada. gov.ua/laws/show/1556-18\#Text

14. "Psychology is the method of laying out the faculty disciplines at the higher school" (2018), the working program of the middle module, the vysoi vysoi svit drukh (magister), the special market 075 "Marketincharama", ONP "Industrial market" i. Igor Sikorsky; way of life. O. V. Vinoslavskaya, Kiev: KPI them. Igor Sikorsky, p. 21, available at:https://ela.kpi.ua/ handle/123456789/26481

15. Romasheva, N. "Gatherings of the problem of the introduction of pedagogical technologies in the initial-vykhovny process", available at:https://scienceandeducation.pdpu.e du.ua/doc/2009/3_2009/16.pdf.pdf

16. "Standard lighting height", available at:https://mon.gov.ua/ua/osvita/vishaosvita/ naukovo-metodichna-radaministerstva-osviti-i-nauki-ukrayini/ zatverdzheni-standarti-vishoyi-osviti

17. Strategy for the highest wave in Ukraine for 2021-2031, available at: https://mon.gov.ua/storage/app/media/rizne/20 20/09/25/rozvitku-vishchoi-osviti-v-ukraini02-10-2020.pdf

18. Baiduc, Rachael, R., Robert A. Linsenmeier, and Nancy Ruggeri (2016),"Mentored Discussions of Teaching: An Introductory Teaching Development Program for Future STEM Faculty", Innovative Higher Education, №41(3)

19. Uzunboylu, H. \& Özcan, D. (2019), "Teaching methods used in special education: A content analysis study", International Journal of Cognitive Research in Science, Engineering and Education (IJCRSEE), №7(2), pp. 99-107

20. Winberg, C. (2018), et al. "Learning to teach STEM disciplines in higher education: a critical review of the literature", Teaching in Higher Education

Стаття надійшла до редколегії 14.05.21 